\title{
Three Feasibility Constraints on the Concept of Justice
}

\author{
Naima Chahboun ${ }^{1}$
}

Published online: 17 October 2016

(C) The Author(s) 2016. This article is published with open access at Springerlink.com

\begin{abstract}
The feasibility constraint on the concept of justice roughly states that a necessary (but not sufficient) condition for something to qualify as a conception of justice is that it is possible to achieve and maintain given the conditions of the human world. In this paper, I propose three alternative interpretations of this constraint that could be derived from different understandings of the Kantian formula 'ought implies can': the ability constraint, the motivational constraint and the institutional constraint. I argue that the three constraints constitute a sequence in the sense that accepting the motivational constraint presupposes that we accept the ability constraint, and to accept the institutional constraint presupposes that we accept both previous constraints. Adding the possibility of rejecting all three constraints, we get four distinct metatheoretical positions that theorists could take vis-àvis the feasibility constraint on justice.
\end{abstract}

Keywords Feasibility · Fact-sensitivity · Ought implies can · Compliance · Realism · Justice

In recent years, scholars have shown a growing interest in the role feasibility constraints play or ought to play in political theory (see e.g. Gilabert 2009; Brennan 2013; Gheaus 2013; Wiens 2014). Feasibility generally concerns the achievability of an ideal, given certain factual conditions (Jensen 2009, pp. 166-167; Gilabert and Lawford-Smith 2012, p. 809). A core question in this debate is whether matters of achievability are distinct from matters of desirability, or if the two - at least in the political domain-are tightly connected in a way that grants feasibility

Naima Chahboun

naima.chahboun@statsvet.su.se

1 Department of Political Science, Stockholm University, Stockholm, Sweden 
considerations the power to undermine the normative status of a proposed principle or ideal. ${ }^{1}$ In particular, theorists disagree as to whether the ideal of justice is conceptually constrained in a way that grants feasibility considerations invalidating power.

The feasibility constraint on the concept of justice roughly states that a necessary (but not sufficient) condition for something to qualify as a conception of justice is that it is possible to achieve and maintain given the conditions of the human world (see Mason 2004; Gheaus 2013). Yet, this leaves open various interpretations of when and why something shall be conceived of as possible or impossible. A common reason why an ideal is not realized is that people, or institutions, fail to comply with its demands. But as is easily recognized, this alone does not show that the ideal cannot be realized. Often, all it shows is that people (or institutions) are behaving unjustly. Still, if a principle will under no conditions be complied with, there seems to be at least something to say for the view that the ideal it envisions is not achievable. The aim of this paper is to examine in which ways foreseeable noncompliance-voluntary or involuntary-with a proposed principle may be held to show that the principle violates the feasibility constraint. Drawing on different understandings of what 'ought implies can' means in political settings, I present three possible interpretations of the feasibility constraint on justice: the ability constraint, the motivational constraint and the institutional constraint. While all three constraints respond to foreseeable noncompliance with proposed principles, the forms of noncompliance vary, as do the reasons for granting them invalidating power. Importantly, I will take no stand for or against the feasibility constraint on the concept of justice. Instead, I will examine different forms that such a constraint could take, if it exists. While ability and motivation commonly figure in competing interpretations of 'ought implies can' (Estlund 2011, 2015; Wiens 2015b), the possibility of creating institutions that assure compliance with justice has, to my knowledge, never been proposed as an independent feasibility constraint. Nonetheless, I believe that what I call the institutional constraint is implicitly present in the reasoning of many authors, in particular those who commit to the view that justice is a specifically 'political' or 'practical' ideal. Through defining and comparing the three forms that the feasibility constraint on justice could take, and identifying the metatheoretical commitments that correspond to each of them, my paper aims to contribute to increased clarity in this tricky conceptual terrain.

Before getting to the task, two clarifications are necessary: first, concerns for noncompliance are often taken to be part of the domain of nonideal theory. Yet, my present concern is not with nonideal theory, at least not in the sense of partial compliance-theory (Rawls 1999, p. 8). ${ }^{2}$ While the noncompliance that gives rise to

\footnotetext{
${ }^{1}$ In contemporary methodological debates, the terms 'ideal' and 'principle' are frequently used but rarely defined. In this paper, a 'political ideal' will allude to the idea of 'the ideally just society', i.e. a society that fulfils the requirements of justice (see e.g. Jensen 2009, p. 168). If a principle or set of principles specifies a specific standard of justice, the corresponding ideal is a world where this standard is fully met.

2 The term 'nonideal theory' is sometimes used in other ways, e.g. to describe comparative as opposed to 'transcendental' accounts of justice (Sen 2006; Stemplowska and Swift 2012). By stating that the feasibility constraint constrains ideal principles of justice, I intend to make no comment on how it relates to nonideal theory in these other senses.
} 
nonideal theory is noncompliance with principles of justice, the noncompliance of interest here is held to disqualify a proposed principle as a principle of justice, i.e. to show that the proposed principle is invalid. Noncompliance thus puts constraints on first, or ideal, principles of justice. ${ }^{3}$ To accept this need not lead us to reject the assumption of full compliance characteristic of ideal theory. It is perfectly possible to combine this assumption, used as a heuristic device for evaluating principles, with a constraint on which principles we may bring up for evaluation (that is, which principles we may assume full compliance with) that is based on foreseeable noncompliance. To take a famous example, such a constraint is introduced by John Rawls's assumption that a conception of justice should generate its own support, given the laws of moral psychology (Rawls 1999, p. 119; Simmons 2010, p. 29). This demand becomes intelligible only if we take the possibility of noncompliance into account; it disqualifies principles which the parties in the original position would otherwise be tempted to choose, given that they assume full compliance with their chosen principles. Whether or not we hold that the assumption of full compliance is motivated at the most ideal level of theorizing - that is, the kind of theorizing that aims to identify first, or fundamental, principles of justice-we may ask if foreseeable noncompliance puts constraints on what justice may demand at this level. ${ }^{4}$

Second, the term 'foreseeable noncompliance' involves an epistemic complication: since the noncompliance of concern here is one that will take place in the future, we can never be absolutely certain that it actually will occur. This raises the question of what counts as foreseeable noncompliance. Is noncompliance foreseeable only when we are (next to) certain that it will occur, or also when we judge its probability sufficiently high, say $75 / 100$ ? Partly in response to the probabilistic nature of claims regarding what we can or cannot do, some authors have suggested that the binary view of feasibility as a matter of either/or should be replaced, or at least complemented, by a scalar account (see Brennan 2013, pp. 321-322; Gilabert and Lawford-Smith 2012, pp. 815-816; Lawford-Smith 2013b, pp. 243-244). How high we set the standards for something to count as feasible will determine which principles are actually ruled out by the feasibility constraint. Yet, since my present aim is simply to distinguish between different possible interpretations of this constraint, not to determine which principles would fail on each account, I can safely leave this problem aside for now.

The paper is structured as follows. The first section introduces the feasibility constraint on the concept of justice. In the following section, 'Three Feasibility

\footnotetext{
3 Every normative approach seems to give rise to a distinction between more and less ideal levels of theorizing. However concessive the standard of justice we opt for, it cannot identify whatever happens to be achievable at any given point in time with justice (Estlund 2008, p. 263; Galston 2010, p. 395). If this is true, the question of what we shall do if justice is not achievable is always present. The less ideal the level of theorizing, the more tragic will the choices that we are facing be (that is, the more injustice will our available options include) (Jubb 2012, p. 234).

4 Note that there may be different reasons for rejecting the assumption of full compliance at this level. While critics of Rawls belonging to the 'realist' camp think that it produces overly idealistic and therefore useless, or even dangerous, political ideals, critics such as Cohen think that Rawls's constructivist apparatus (to which the assumption of full compliance belongs) confuses fundamental principles with applied principles, and thereby fails to uncover what pure justice requires.
} 
Constraints', I present three possible interpretations of this constraint that arise from different understandings of 'ought implies can'; the ability constraint, the motivational constraint and the institutional constraint. 'The Institutional Constraint, Some Clarifications' offers a closer examination of the institutional constraint, which states that a principle may qualify as a principle of justice only if we could ensure compliance with it through the creation of coercive institutions. This discussion gives rise to the further question of how we should perceive the potential moral costs of assuring compliance with justice. 'The Moral Costs of Assuring Compliance' examines this problem, while 'Feasibility, not Fact-Sensitivity' addresses a possible objection to my argument so far. In 'Four Metatheoretical Positions' I present four metatheoretical positions that theorists could take vis-à-vis the feasibility constraint on justice. The last section summarizes my conclusions.

\section{The Feasibility Constraint on the Concept of Justice}

The feasibility constraint on the concept of justice is often held to follow from the Kantian formula 'ought implies can', which restricts the set of obligations an agent may have (Jensen 2009, p. 168). If I cannot do X, the thought goes, I cannot have a moral obligation to do X. Accordingly, advocates of the feasibility constraint on justice argue that justice cannot require that which we, individually or collectively, cannot achieve (Gheaus 2013, p. 446; Brennan 2013, p. 322). The claim is not simply that a principle cannot give rise to an 'ought' unless the factual circumstances permit this, that is, a claim about when and how a principle could be applied. Rather, what is at stake is whether justice could demand something that we could never achieve, given the conditions of the human world. ${ }^{5}$

Whether or not we accept the feasibility constraint on justice depends largely on what kind of thing we think justice is, and whether or not we think that justice has a practical purpose (or, indeed, any purpose at all) (Cohen 2008, p. 267; Stemplowska and Swift 2012, p. 384). While an epistemic approach perceives of justice as a philosophical ideal that may or may not have practical implications, a practical approach holds that justice is the solution to a political problem and closely tied to the justification of power (Rawls 1980, p. 517; 1999, p. 39; 2001, p. 2; Cohen 2008, pp . 267, 327; Galston 2010, p. 390; Stemplowska and Swift 2012, p. 274). On the former, the domain of justice includes purely evaluative claims (that we shall not necessarily act on), whereas on the latter, all justice claims are prescriptive (i.e. action-guiding) ${ }^{6}$ (Farrelly 2007, p. 845; Gilabert 2011, pp. 56-57; Stemplowska

\footnotetext{
5 This also means that the ideally feasible includes not only that which is directly feasible at one specific point in time, but also that which is indirectly possible to achieve through a chain of actions. Since every relevant sense of 'can' includes both first- and second-order abilities, ideal justice may give rise to dynamic duties, including duties to expand the feasible set of actions (see Jensen 2009, p. 176; Gilabert 2009, p. 677).

${ }^{6}$ If justice includes evaluative claims, we may distinguish between fundamental and applied principles of justice, or between principles of justice and rules of regulation or institutional proposals (Cohen 2008, pp. 253, 279-280; Estlund 2011, p. 215). If, to the contrary, justice claims are always prescriptive, we will hold that principles of justice, by their very nature, are applied and regulative for social institutions (See Schmidtz 2011, p. 779).
} 
2008, pp. 334-335; Miller 2013, p. 34). In order for a claim to be prescriptive, it must be prescriptive for someone. On the practical account, then, justice is a quality of the conduct of agents, and there can be no injustice where no agent is violating any obligation of hers ${ }^{7}$ (Anderson 2010, p. 5). This explains why the practical approach is committed to the feasibility constraint on justice: if justice is a quality of the conduct of agents, it is also conceptually constrained by 'ought implies can' (but see Mason 2004, p. 257). Still, if every obstacle that may hinder any agent at any point in time from acting on a principle would be allowed to constrain the concept of justice, justice could hardly demand anything at all. Instead of providing action-guiding recommendations for all possible circumstances, then, ideal principles of justice should guide our actions in the most favorable circumstances that we could realistically hope for (henceforth: 'ideal circumstances') ${ }^{9}$ (Rawls 1999, p. 176; Mason 2004, p. 252. See also Wiens 2015a, p. 437; Chahboun 2015, p. 235).

Yet, to know what makes us accept or reject the feasibility constraint on justice tells us nothing about what this constraint actually rules out. As stated previously, I will here examine if and when foreseeable noncompliance with a proposed principle of justice shows that the principle violates the feasibility constraint. If justice can only demand that which we, in ideal circumstances, can bring about, foreseeable noncompliance will disqualify a proposed principle of justice if the noncompliance follows from the fact that we cannot comply. But what exactly does 'cannot' mean? As we shall see, there are several possible replies to this question, producing various constraints on the concept of justice.

\section{Three Feasibility Constraints}

Whether a proposed principle violates 'ought implies can' or not depends on what, exactly, we mean by 'can'. 'Can' always refers to the capacity of a specific, individual or collective, agent (Lawford-Smith 2013b, p. 247). For simplicity, I will assume that in political settings, the relevant agents are individual citizens or groups of citizens (acting collectively) of a state. What, then, does it mean that an agent of this kind 'can' do something? As David Estlund notes, two competing

\footnotetext{
7 Some may protest that obligations never spring directly from ideals and principles, but always from an application of these principles which also incorporates concerns for empirical constraints. If ideal justice is the state of affairs $\mathrm{X}$, then the action-guiding recommendation corresponding to this ideal is not 'realize $\mathrm{X}$ ', but 'realize $\mathrm{X}$ to the extent that it is possible'. As previously stated, I think that this distinction between applied and fundamental principles is precisely what the practical approach denies.

${ }^{8}$ I thus disagree with Anca Gheaus's view that rejecting the feasibility constraint could enhance the action-guiding potential of justice 'by providing an aspirational ideal' (Gheaus 2013, p. 448). In order for an ideal to be aspirational, it must be feasible in at least the strictest sense of the term. To reject the feasibility constraint on justice as such (and not only some of the possible senses of 'can' discussed in this paper) is thus to accept that justice may be not only a 'hopeless', but also an impossible ideal (Estlund 2008, pp. 264-267; see also Wiens 2014).

9 Cohen (2008, p. 280) rejects the identification of first or fundamental principles with those that apply in ideal circumstances. In his view, applied principles are constituted by a mix of fundamental principles and facts. Hence, applied principles are never fundamental, and fundamental principles do not apply to any particular circumstances. Since my concern here is with views that disagree with Cohen on this point, I will make no assessment of his critique.
} 
understandings of 'can' feature in the contemporary literature. On what we may call the wide reading, 'can' refers to all acts that we can do, as a matter of physical or mental ability (depending on the act). On this view, 'cannot' refers to acts which we, even if we were to try and not give up, would not tend to succeed in performing (Estlund 2011, p. 210). I will call the feasibility constraint resulting from the wide understanding of 'can' the ability constraint on justice.

The ability constraint: if a proposed principle demands that which we, even under ideal circumstances, cannot do (even if we were to try and not give up), it must be rejected as a principle of justice.

On the wide reading of 'can', the feasible includes all those acts that we, the members of a society, could, individually or collectively, perform given that we all were to try and not give up. Since trying is assumed on this account, the noncompliance involved here may be characterized as involuntary. In the case of justice, two different kinds of inability may be held to produce involuntary noncompliance. The first is the inability to know which acts would bring justice about (even if we could perform these acts, would we only know which they were). The other is the inability to perform the required act (even if we know that it would bring justice about). Views diverge as to whether or not the first of these inabilities (call it 'epistemic inability') really shows that a principle of justice violates 'ought implies can' (see Howard-Snyder 1997; Carlson 1999). Whether or not we include epistemic inability in our definition will have great implications for which principles are ruled out by the ability constraint. But again, since my present aim is simply to conceptually distinguish this from other possible interpretations of the feasibility constraint on justice, not to determine its scope, I need to take no stand on this issue.

On the second, narrow, reading, 'can' instead refers to those acts that we can bring ourselves to do, that is, to the acts that we can will to do. On the narrow reading, whether or not we can do something depends on our ability to motivate ourselves to do it (Estlund 2011, pp. 210-212). As everybody knows, the motivation to fulfil one's duties varies highly among individuals. Still, what we can will is different from what we simply want; mere weakness of will cannot relieve us from our duties. Rather than tracking the actual moral capacities of individuals, the narrow understanding of 'can' is commonly held to include all things that we as human beings can bring ourselves to do given our most fundamental, common psychological traits, often summoned under the label 'human nature' (see Nagel 1991, p. 6; Galston 2010, p. 406; Estlund 2011, pp. 210-212; Hall 2013, p. 178; Miller 2013, p. 16). This seems to render what we can do a matter of statistical probability; we ground our assumptions of which acts are feasible on the frequency of their occurrence in the historical record of humanity. In this sense, ought, on the narrow reading of can, implies 'reasonably likely' (Estlund 2008, p. 265; LawfordSmith 2013b, pp. 253-254; Wiens 2015b). Very few acts, it would seem, are ruled out because no human being can bring herself to perform them. Some people voluntarily live in chastity and poverty, risk their lives trying to rescue others, donate one of their kidneys to a stranger or give away their children to common custody. And even if we may call such persons exceptional in various ways, we usually have no reason to call their humanity into question (see Estlund 2011, 
pp. 221-222). Still, most people would be unable to bring themselves to perform such acts, and this has led defenders of the narrow reading to conclude that a demand to do so would violate 'ought implies can'. I will call the feasibility constraint resulting from the narrow understanding of 'can' the motivational constraint on justice.

The motivational constraint: if a proposed principle demands that which human beings generally, even under ideal circumstances, are unable to bring themselves to do, it must be rejected as a principle of justice.

On the narrow reading of 'can', the feasible includes those acts that we, the members of society, could bring ourselves to perform, individually and collectively, given the common psychological traits constitutive of our human nature. Critics of this view have argued that it produces an overly concessive understanding of justice and that the intellectual process leading us to affirm it constitutes a form of 'adaptive preference formation' (Cohen 1995, p. 253). Why, we may ask, should the mere fact that people, due to some natural inclination, cannot motivate themselves to do something lead us to conclude that this act is not a requirement of justice? Why not rather conclude that people are naturally inclined towards injustice? (Estlund 2011, p. 224; Mason 2004, p. 260). One possible reply states that if justice is action-guiding for political institutions, and the purpose of such institutions is to mitigate the effects of our limited capacity for altruistic behavior, then principles of justice must concede to this aspect of human nature rather than condemn it. If a proposed principle ignores human nature, it will never provide the guidance needed to inform political action, since politics is a response to problems that arise precisely due to human nature (see Gilabert and Lawford-Smith 2012, p. 813; Miller 2013, pp. 25-26). Another possible defence of the narrow reading rejects the distinction between 'can do' and 'can will to do', and argues that 'can do', on all plausible readings, actually entails 'can will to do' (see Wiens 2015b). To determine the real status of the narrow reading of 'can' falls outside the scope of this paper. For my present purposes, it suffices to convince the reader that the motivational constraint constitutes a serious proposal worthy of consideration. I hope hereby to have done so.

Apart from the wide and narrow readings, we may distinguish between self- and other-oriented understandings of 'can'. If an account of justice prescribes that a person performs certain acts without showing any interest in her reasons for so doing (reasons that would be crucial to conceptions of justice that also place demands on persons' intentions or virtues), what is feasible is not only a matter of what this person can do or will to do, but also of what she can be brought to do by others (Lawford-Smith 2013b, p. 251). A possible justification of this understanding of 'can' may be borrowed from the growing field of realist political theory. Realists criticize idealists for mistaking politics for morality, and urge us to recognize politics as a domain characterized by conflict and power struggle (Geuss 2008, p. 25; Horton 2010, p. 434; Rossi 2010, p. 504; Philp 2012, p. 633). This seems to entail recognizing that which political ideals we are able to realize is a matter not only of what we (the members of society) can do or will to do, but also of what we (the promotors of a particular political ideal) can make others (our antagonists) do, 
despite their initial or persistent denial of these acts' desirability (see Galston 2010, p. 395; Horton 2010, p. 443; Sleat 2013, pp. 53-55). In what follows, I will assume that in political settings our means for making others do things are mainly institutional. If we think that politics is a domain characterized by conflicting interests and profound disagreement resulting in power struggle, then, a solution to the political problem must include institutional arrangements that have the power to make those comply who do not themselves affirm the principles or ideals that the institutions embody. On the view that I am proposing, 'can' in political settings thus refers to those acts that we can make others do through the creation of controlling and coercive institutions. ${ }^{10}$ If, even in ideal circumstances, no institutional arrangement that we ('the vanguard of justice') could bring about would make dissenters comply with a proposed principle, the principle will be rejected. For simplicity, I will here assume that all institutional arrangements that could be put in place by human beings (in ideal circumstances) are available also to the vanguard of justice. ${ }^{11}$ This assumption does not sidestep the problem at hand, since, once in place, the institutions would still be required to possess the controlling and coercing powers necessary to make potential noncompliers comply. I will call the feasibility constraint resulting from the other-regarding understanding of 'can' the institutional constraint on justice (see Mason 2004, p. 256; Barry and Valentini 2009, p. 508).

The institutional constraint: if a proposed principle demands that which we, even under ideal circumstances, are unable to make others do (through the creation of coercive institutions), it must be rejected as a principle of justice.

Note that our inability to make others do something need not correspond to any inability on their part. There may be things that human beings could easily do or bring themselves to do which we will never be able to make them do. Noncompliance due to mere weakness of will may, on this view, render an ideal infeasible, and thus the principle that recommends it invalid, if no institutional arrangement could make the noncompliers comply. ${ }^{12}$

Of the three constraints I have presented, the institutional constraint is probably the least familiar and most controversial one. In order to avoid misunderstandings

\footnotetext{
${ }^{10}$ Another possible distinction is the one between that which we, as citizens, can do or will to do, and that which we can make ourselves do only through creating such institutions. It is, for instance, perfectly possible to imagine someone who is unable to bring herself to perform some action A, but still can motivate herself to vote for a law that forces her to do A (hence, she can will to will to do A even if she cannot will to do it). For reasons explained below, I will assume that if someone can will to will to do something in this sense, she can also will to do it.

11 There are at least two different situations in which such an institutional arrangement does not exist: first, where no institutional arrangement could produce the desired outcome, and, second, where the only arrangement that could do so would fail to generate even the minimal support that is required for it not to be overthrown by its dissenters. I treat these cases together, since they have in common what is crucial for my argument, namely that any attempt to make others comply with standards of justice through the creation of controlling and coercive institutions will fail.

12 Some would probably say that this assumption per definition renders an account of justice nonideal (see e.g. Lawford-Smith 2013a, pp. 653-654). The sense in which I talk about ideal principles here, however, simply states that these are principles of justice which do not respond to a failure to comply with some other principle of justice. They are, in this specific sense, first principles of justice.
} 
and respond to some immediate objections it is likely to provoke, the following section explains this idea in further detail.

\section{The Institutional Constraint, Some Clarifications}

In order to avoid confusion, the institutional constraint should be distinguished from three related, but non-identical, views. First, the institutional constraint is distinct from institutionalism, i.e. the view that principles of justice apply exclusively to social institutions and not to individual choices within these institutions (apart from the choice of complying or not with the rules set by the institutions) (Rawls 1999, pp. 7, 99; Cohen 1997, p. 3; Nagel 1991, p. 18). While the institutional constraint seems to presuppose that we accept institutionalism (why else think that the feasibility of institutional arrangements put constraints on justice?), the reverse is not true: even on an institutionalist account, the rules set by just institutions may be such that they demand more than citizens will ever comply with, or even more than they can or can will to comply with. While accepting institutionalism seems like a necessary condition for accepting the institutional constraint, it thus provides less than sufficient reason for doing so. Second, the institutional constraint is distinct from what may be called the associative account of justice, i.e. the view that justice applies only to the specific relations that arise among people who live under shared coercive institutions. On this view, institutional arrangements are not merely means for realizing justice; they are the very origin of justice relations between individuals (Nagel 2005, pp. 120-121). Later in this section, I will argue that a common defence of the associative view also offers a reason to accept the institutional constraint. Still, the two are different, since the associative view privileges actually existing institutions by assuming that relations of justice appear exclusively within their realm. ${ }^{13}$ The institutional constraint implies nothing of the kind. It considers only whether or not a required institutional arrangement could be put in place in ideal circumstances, not if it currently exists. Third, the institutional constraint is distinct from practice-dependence, according to which the content, scope and justification of political ideals are determined by existing practices and institutions (Sangiovanni 2008, p. 138). Practice-dependence, or at least one version of it, incorporates both institutionalism and what I have called the associative view of justice (see Sangiovanni 2008, p. 138, 140). But it adds to these the view that ideals are identified and justified through an interpretative process which (1) carefully describes the point and purpose of an existing institutional system, and (2) from that description presents an argument of what the institutional system should be like (Sangiovanni 2008, pp. 142-143). That ideals are extracted from existing institutions does not entail that those institutions are able to fully realize their point and purpose (if so, there would be no need for the second step of interpretation), nor does it seem to entail that any feasible institutional arrangement could do so. Part of the point and purpose of the institution of the last anointing is to

\footnotetext{
13 For the view that existing institutions may constitute a 'soft' feasibility constraint, see Lawford-Smith (2013b, p. 255).
} 
absolve the dying person of her sins and prepare her for the passage over to the afterlife. Part of the point and purpose of the UN Security Council is to secure world peace. Yet, it is doubtful whether any institutional arrangement could successfully provide any of these outcomes. Hence, to affirm practice-dependence does not necessarily entail that we affirm the institutional constraint.

Further, I have claimed that the institutional constraint is distinct from the motivational constraint. But is it really? What if the only things we cannot, in ideal circumstances, make others do are those that violate human nature? Perhaps one could even argue that the only way for us to see that a proposed principle violates human nature is through the realization that no institutional arrangement could ensure compliance with it. Take the previous example of giving away your children to communal upbringing as a case in point. I agree that this objection has a certain appeal. Still, the definition it proposes strikes me as overly strict. Surely, there are things that we could bring ourselves to do that no institutional arrangement could make us do. To exemplify, take the act consequentialist proposal that justice demands that we grant equal consideration to the interests of all people, including ourselves, when making decisions in our everyday life. Setting aside the epistemic problem of how to know how different decisions affect the interests of others, I think most would agree that this principle demands more than most people could bring themselves to do. ${ }^{14}$ It violates, in other words, the motivational constraint on justice. Now, take the slightly different proposal that we must grant not equal, but still some, consideration to the interest of others when making everyday decisions (Scheffler 1994, p. 20). To be sure, the demandingness of this proposal depends on exactly how much consideration we are to grant the interest of others, but it is easy to think of versions of this ideal that does not conflict with human nature. Still, it is hard to see what kind of institutional arrangement could make people comply with it. Even assuming that we could easily tell whether or not a specific decision conforms with the principle, the mere vastness of decisions (not to mention nondecisions) facing persons in their everyday life would render it impossible to keep a record over the decisions made by every member of a society. And if we cannot tell compliers from noncompliers, no institutional arrangement is likely to be able to render sufficiently sure that enough people will comply. One may object that even in the absence of effective control mechanisms there may be institutional arrangements that could make people comply, not by forcing them to do so, but by convincing them of the moral rightness of the principle or ideal in question. To inform persons' moral views is undoubtedly a crucial task not only of educative, but also of legal and retributive institutions. Yet, recall that what I have called the institutional constraint assumes permanent dissensus on moral and political ideals. Institutions that could make others comply are necessary precisely because we acknowledge that these others will deny the moral status of our proposed principle. For this reason, the controlling and coercive aspects of institutions are crucial for the institutional constraint. Does the assumption of permanent dissensus contradict my previous

\footnotetext{
${ }^{14}$ Note that this critique is different from the common objection that act consequentialism undermines agents' integrity, though this too, often falls back on the notion of 'human nature' (see Scheffler 1994, pp. 3, 7-8).
} 
assertion that the constraints on justice here considered apply also in ideal circumstances? No. Recall that we defined ideal circumstances as the best circumstances that we could realistically hope for. On the realist view, we could never realistically hope for something like a 'rational' or 'overlapping' consensus on what justice requires, and this is why the lack of feasible institutional arrangements that could make dissenters comply will invalidate a proposed principle of justice.

Last, the differentiation between an 'us' who are already motivated to build just institutions and a 'them' who should be incentivized to comply with them seems troubling from a normative point of view. It cries out for an investigation of who the bearer of political duties is. Even if we accept that we (the vanguard of justice) cannot have an obligation to make others comply with the demands of justice if we do not have the ability to make them do so, it is far from obvious that these others have no obligation to comply (cf. Lawford-Smith 2013a, pp. 659-660). Of course, we could take it as a given that they simply will not fulfil this obligation and ask what justice demands of us to do in this case. But this would distance us from the assumption of ideal circumstances, and thus render our inquiry one about nonideal theory alone. To assume that our present obligations are the result of a previously unfulfilled obligation presupposes a more ideal level of theorizing where noncompliance with this obligation is not taken for granted. If it is true that we must take noncompliance into consideration even at the most ideal level of theorizing, noncompliers can have no duty to comply even though we (the vanguard of justice) have a duty to make them do so. But why, one may ask, accept the seemingly aristocratic idea that political obligations fall only on the vanguard of justice $?^{15}$ Surely, such obligations must be shared by all (or most), and not only some, members of a political community? ${ }^{16}$ I certainly do not wish to suggest that only those who value (a particular conception of) justice have a duty to comply with its demands. Still, there might be a way to arrive at the institutional constraint on justice. This passes through the observation that principles of justice give rise to collective rather than individual obligations, and that for collective obligations to distribute to individuals, some likelihood that other members of the collective will comply is required. Since collective acts are made up by several individual acts, there will always be a minimum of individuals required for a collective act to take place. If you and I have a collective duty to move a dining table, but you will not fulfil your part of the duty, I cannot fulfil mine (given that I cannot lift the table on my own). Even if I try, what I end up doing is not 'helping to move the table' but futilely pulling one end of it. Only if other members of the collective fulfil their shares of a duty, or, on an internalist view, if we have reason to believe that they will do so, are we required to do ours (Lawford-Smith 2012, pp. 456-457). This insight may lead to the conclusion that collective duties only distribute to individuals when there is some sort of assurance that others will contribute their

\footnotetext{
15 If society is organized in a way that concentrates political power in the hands of a few, these arguably have a greater responsibility than the powerless majority for directing society towards the ideal. Still, this does not mean that if the minority tries to bring justice about, the majority has no duty to help.

16 Yet, see Philp (2010) who seems to hold that political theory should provide action-guiding recommendations specifically for politicians.
} 
share. And one way to arrive at this kind of assurance is through the creation of state institutions which provide incentives to comply. This brings us back to what I have called the associative account of justice. On this view, justice requires coordinated collective action that can only be sufficiently assured through legal institutions backed up by a monopoly of force. Thomas Nagel offers two separate justifications for this view: first, if there is no assurance that others will comply with the demands of justice, individuals will lack a reason to comply, since only when all comply will the collective interest coincide with the individuals' self-interest. This justification falls back on the Hobbesian assumption that duties must be possible to motivate through appeal to self-interest. But even if we reject the Hobbesian view, Nagel maintains that our obligations are dependent on some sort of assurance that our acts are part of a reliable and effective system. The idea is not simply that absent such assurance and individuals will lack the motive to do what justice requires, but also-and importantly - that they will lack the opportunity to do so (Nagel 2005, pp. 115-116). This is the problem of collective duties; if not enough people contribute, we cannot do what would ideally be required by us (helping to move the table rather than pulling its end). If we think that principles of justice, in ideal circumstances, must translate perfectly (that is, without the loss indicating a move from ideal to nonideal theory) into obligations of individual agents, we must therefore reject principles which demand that which we cannot make others do, through the creation of coercive institutions (cf. Mason 2004, pp. 256-257). Though far from conclusive, I think this offers a fairly convincing provisional defence of the institutional constraint-convincing enough for us to consider this position seriously. But to accept the institutional constraint on justice brings us to a further problem. What if the only institutions that can assure the compliance necessary for collective obligations to distribute to individuals are themselves undesirable? This undoubtedly sounds like a matter of desirability rather than feasibility. Yet, as I will show, if it is not a feasibility problem, it is hard to see why we should think it is a problem at all.

\section{The Moral Costs of Assuring Compliance}

According to the institutional constraint on justice, the acceptability of an ideal depends on what we can make others do, through the creation of controlling and coercive institutions. Now, what we can make others do is often a matter of how powerful our means for convincing them to do it are. Suppose that a proposed principle of justice requires that people contribute to society according to their ability. Suppose further that the only way for us to make dissenters comply with this principle is to torture them. Given that torture could be institutionalized, the proposed principle does not violate the institutional constraint. Yet, to torture people seems like a morally outrageous thing to do. And this brings us to the problem of moral costs of assuring compliance with justice. The idea is this: if it would be absurd to suggest that we have a moral obligation to torture people, it would be equally absurd to suggest that we have an obligation to make people contribute according to ability if torture is the only way for us to achieve this outcome. If it is 
possible to enforce a principle only through deeply undesirable means, such as extensive surveillance, coercive indoctrination, shameful revelations or threats of brutal punishments, it would be absurd to affirm this principle as a principle of justice (see Wolff 1998, p. 114; Rawls 1999, p. 452; Mason 2004, p. 256; Schmidtz 2011, p. 788; Hall 2013, pp. 177-178; Jubb 2015, p. 929). The problem arises because justice is often perceived both as a quality of political institutions, and the effects of these institutions on society. Let us say that a tax system is just if it brings about a certain distributive pattern. Yet, apart from producing this pattern, a just tax system must also not violate people's integrity by, for instance, letting taxmen break into people's homes in order to disclose attempts at tax evasion. This seems to suggest that apart from the three aforementioned constraints, there is a forth, moral cost-constraint, on justice. I will soon proceed to show why this conclusion is mistaken. First, however, I want to grant that the proposed objection is not, at least not necessarily, a sign of mere conceptual confusion. Some would argue that the moral cost-objection confuses the desirability of a principle with its enforceability. What people ought to do and what others (the state) have a right to make people do, they would say, are two entirely different things. The mere fact that I have a duty to do something does not sanction you forcing me to do it. In some cases at least, I have a right not to be forced to do my moral duty (Otsuka 2008, p. 449). Yet, the status of this right seems less clear when it comes to political duties. Many theorists agree with Kant that duties of justice are by definition those that may be institutionalized and enforced (see e.g. Tan 2004, p. 361). For the sake of argument, I will here accept the Kantian view. By doing so, I grant that the moral costs of ensuring compliance with a principle could, on some accounts, affect its desirability. But this does not warrant a separate moral cost-constraint, since, as I intend to show, the problem this is supposed to address is already covered by the institutional feasibility constraint.

Juha Räikkä has suggested that if an ideal can be realized only at high moral costs, this may give rise to a special kind of feasibility constraint. 'When the necessary moral costs of changeover are taken into account in the evaluation of feasibility', he argues, 'it becomes partly a normative matter to decide which institutional arrangements are feasible and which are not' (Räikkä 1998, p. 37). Räikkä's argument is specifically about transition costs. But since matters of transition are part of nonideal rather than ideal theory, the for us more urgent problem is what would happen if assuring compliance with justice would continue to be morally costly once the initial transfer from unjust to just institutions were completed. I see no problem with extending Räikkä's proposal to this slightly different situation. Still, I think we have good reasons to resist the idea of moral feasibility constraints of the kind Räikkä points to. As argued by Gilabert and Lawford-Smith, however strong we hold the moral reasons against something to be, they do not have the metaphysical status to ensure that a proposed ideal cannot be realized (Gilabert and Lawford-Smith 2012, p. 817; see also Brennan 2013, p. 328). Recall that the claim of concern here is that justice is restricted not only by what we can bring about, but also by what we can bring about through reasonable means. Rather than feasibility, this looks like a matter of desirability. Must the means needed to realize justice (rather than justice itself) be desirable? In other words, are 
the costs of assuring compliance with just institutions (under ideal circumstances) internal or external to justice itself? (Hall 2013, p. 176). How we respond to this question seems largely dependent on whether we perceive of justice as 'all-thingsconsidered' or not.

Justice as all-things-considered is most easily understood in contrast to what is commonly termed value pluralism. For defenders of the pluralist view, justice is not the 'first virtue of social institutions', but only one among several values which are not only distinct but may also conflict (Cohen 2008, p. 286; cf. Rawls 1999, p. 3). While all are valuable, none is worth pursuing at all costs. We commonly think about values, even political values, in this way. Take, for instance, freedom and security. While both are valuable, most agree that they must be balanced against each other to reach a morally optimal outcome. To accept this is not to say that the optimal level of freedom (when balanced against security) constitutes 'real' or 'political' freedom. It is simply to say that this is the right amount of freedom given the necessary trade-off. Yet, Rawls has taught us to think of justice differently, as an ideal which gives rise to individual claim rights and which must therefore not be compromised but for the sake of justice itself. Rather than trading justice off against other values, Rawls calls the outcome of the trade-off among different values 'justice' (Cohen 2008, pp. 303-305).

The pluralist view can easily deal with the moral costs of bringing justice about. Since justice is just one value among many, it will need to be traded off against others in order to reach a morally optimal outcome. How much justice we should bring about simply depends on how costly the trade-off against other values is (Cohen 2008, p. 327). For pluralists, then, the 'problem' of moral costs is actually not a problem at all. In addition, if we do not know that full justice is desirable (given the necessary costs), we seem to have no reason to assume that there must be feasible institutional arrangements that can assure this outcome. Advocates of the pluralist view should therefore reject not only the proposed moral cost-constraint but also the institutional constraint on justice.

It is only when perceived in the 'all-things-considered' sense that we have reasons to assume that justice, under ideal circumstances, must be possible to pursue without significant moral costs (see Gilabert 2011, p. 57). Yet, a closer look upon this reveals something surprising: if justice is all-things-considered, it seems as if the problem of moral costs either dissolves or is captured by the institutional constraint. If justice denotes the optimal trade-off between some values, say freedom and equality, any infringement on one of these values becomes a conflict internal to justice itself. If the realization of one of aspect of justice (say, a certain distribution of primary goods) would require a violation of another aspect (say, everyone's equal freedom), the proposed conception of justice is infeasible. One may think that this shows that the moral costs of assuring compliance with justice, contrary to what I have argued, actually constrains the feasibility of an ideal. But this would be a mistake, since what it really shows is that full justice is not merely too costly, but impossible to bring about. The moral costs of assuring compliance are no longer costs of assuring compliance with justice, but only with one aspect of justice. If assuring compliance with one aspect of an ideal requires violation of another of its aspects (in ideal circumstances), then the ideal is clearly infeasible. 
Since, in this imagined scenario, no institutional arrangement can realize full justice, the proposed moral cost-constraint thus turns out to be an institutional constraint.

In order for the problem of moral costs to arise, we must assume that assuring compliance requires a violation of some value that is not included in the relevant trade-off constitutive of justice. But whatever value that would be, its violation is a bullet which defenders of the all-things-considered account should happily bite. If justice (in ideal circumstances) trumps other values, which should be presumed on an all-things-considered account (why bother to make the trade-off constitutive of justice if only to then trade this off against other values?), this value, whatever it is, will simply be overridden. If the problem of moral costs is not a feasibility problem, it seems as if it is no problem at all. ${ }^{17}$

\section{Feasibility, not Fact-Sensitivity}

I have argued that what one could mistakenly think of as a moral cost-constraint is actually an instance of the institutional constraint which occurs if we hold that principles of justice provide all-things-considered recommendations for political institutions. This section anticipates and responds to a possible objection to this argument. The objection states that the problem of moral costs is not limited to the all-things-considered account of justice. Even on the pluralist account, we should reject ideals that are too costly to realize since principles of justice are justified only when the effects of applying them to the world coincide with our considered convictions about justice. Contrary to what I have argued, the problem of moral costs is not a matter of feasibility, but instead concerns the fact-sensitivity of normative principles and ideals. While the former may be treated as a secondary matter external to justice itself, the latter determines the normative status of principles and must therefore be incorporated in every serious attempt to assess a proposed principle of justice (see Farrelly 2007, p. 844; Hall 2013, p. 177).

The distinction between fact-sensitive and fact-insensitive metaethical approaches concerns our reasons for affirming principles. According to the factsensitive approach, principles of justice are justified only in light of the facts of the world (Rawls 1999, p. 137; Cohen 2008, p. 259). In order to know if we shall affirm a proposed principle, then, we must consider its effects when applied to the world as we know it (see Jubb 2009, p. 345; Hall 2013, p. 176). Let us, for the sake of argument, assume that this is true. Even so, I think that the objection fails, since to consider the effects of a principle here means to consider the effects of complying with the principle. This is clearly shown by Rawls's defence of the difference

\footnotetext{
17 Geoffrey Brennan suggests that what we shall do always is a matter of optimization. On the optimizing view, he argues, 'claims about costs are claims that invoke both feasibility and desirability considerations in equal measure' (Brennan 2013, p. 328). As shown by my argument above, this conclusion strikes me as mistaken. If what we shall do is a matter of optimization of different values, the problem of costs will neither affect the feasibility, nor the desirability of the values involved. The fact that we should not realize $\mathrm{X}$ because doing so means that we would have to forego $\mathrm{Y}$ neither shows that $\mathrm{X}$ is infeasible, nor that it is undesirable. Rather, what it shows is that not-Y is undesirable, and more so than not-X. If, on the other hand, a proposed trade-off between $\mathrm{X}$ and $\mathrm{Y}$ would be too costly in terms of either $\mathrm{X}$ or $\mathrm{Y}$ (or Z), this only shows that the trade-off is suboptimal.
} 
principle, in response to which Cohen formulates his fact-insensitivity thesis. The difference principle states that inequalities are just if (and only if) they benefit the worst-off. Applying this principle to the world as we know it will, Rawls asserts, produces a fairly egalitarian distribution of primary goods. The distribution of natural endowments and the workings of open markets will, as a matter of fact, prevent a concentration of resources in the hands of the few (Rawls 1999, p. 137). Though we can easily see how the difference principle could come to justify great inequalities if applied to a world where markets were working differently, or where natural assets were distributed in a different way, such counterfactual considerations have-according to defenders of the fact-sensitive approach-no implications for its status as a fundamental principle of justice ${ }^{18}$ (Rawls 1999, p. 137; Valentini 2012, p. 658; Miller 2013, p. 23, 26; cf. Cohen 2008, p. 259). That the fact-sensitive approach asks us to consider the effects of complying rather than not complying with a principle is no coincidence. Since to consider the effects of not, or only partially, complying with a principle is always also to consider the effects of complying with a different principle, the assumption of full compliance is necessary in order for us to know which principle we are assessing (see Simmons 2010, pp. 8-9). The moral cost-constraint states that if the costs of assuring compliance with a principle are too high, the principle must be rejected as a principle of justice. But since the fact-sensitive approach assumes full compliance with the principle subject to evaluation, it fails to recognize any such costs. Hence, fact-sensitivity provides no reason to affirm the proposed moral cost-constraint. ${ }^{19}$

To further clarify the distinction between feasibility and fact-sensitivity, think of two possible objections to the socialist principle 'from each according to his ability, to each according to his need'. The first objection states that no feasible institutional arrangement can produce this distribution. The reason why this is so is largely unimportant, but let us assume that there are no secure ways of measuring abilities and needs, and that people will constantly underrate their abilities and exaggerate their needs. The ideal the socialist principle prescribes would then be unachievable through the means available through institutional arrangements, and this would lead advocates of the institutional constraint to reject it as a principle of justice. The second objection instead concerns the ability of the socialist principle to capture our considered convictions about justice. Suppose that the socialist principle matches our considered convictions about justice when applied to the world as we know it.

\footnotetext{
18 This is true if the difference principle is considered alone. Yet, Rawls insists that it cannot be assessed in this way: the difference principle assumes the workings of the other principles of justice (the liberty principle and the principle of equal opportunity). In this setting, he argues, massive inequalities could never arise (Rawls 1999, p. 136). Since Rawls thus offers a principled argument for why the difference principle not only will not, but also could not allow great inequalities, it seems as if he would not have to affirm the fact-sensitive approach in order to defend the difference principle. Yet, since he does affirm it, and since the status of the difference principle is not what is at stake here, I will set this complication aside for now.

19 As explained in the introduction to this paper, the feasibility constraint does not stand in contradiction with the assumption of full compliance, used as a heuristic device. Still, in order for the fact-sensitive approach to address the problem of moral costs, it would have to qualify this assumption in the same way as the ability, motivational and institutional constraints. Since it operates on the assumption of full compliance, the fact-sensitive evaluation of principles fails to produce any such qualification.
} 
Suppose further that if, in a different world, a few extremely needy persons' needs would enslave the rest of the population, making them work at the top of their capacity for only minimal compensation, the socialist principle would strike us as unjust. In this case, advocates of the fact-insensitive approach would reject the socialist principle as a fundamental principle of justice, while defenders of the factsensitive approach could still affirm it as such. Note further that none of these views would be committed to reject the socialist principle as an applied (non-fundamental) principle of justice, given the prevailing factual circumstances. Both could agree that socialist justice is a normative ideal for us here and now, though defenders of the fact-insensitivity thesis would insist that it could not tell us the whole truth about justice. If we instead assume that the needy few would swallow all resources in this world, and, as a result, the socialist principle would not capture our considered convictions about justice here and now, the fact-insensitive approach would still not allow us to affirm socialist justice only because there could be another world where the outcome would provide the relevant match. Fact-insensitivity about grounding is not about denying the normative importance of the facts of the world, it is simply to say that there is something beyond the applied principles that we affirm in light of these facts (Cohen 2008, pp. 279-280).

The disagreement between advocates of fact-sensitive and fact-insensitive approaches to justice, then, has nothing to do with the costs of assuring compliance. This, I have argued, is a feasibility constraint which appears if we assume that justice should provide all-things-considered recommendations for political institutions (cf. Jubb 2012, p. 238). Though justice as all-things-considered is likely to attract more defenders of fact-sensitive than of fact-insensitive approaches, I see no reason to think that advocates of the fact-sensitive approach must be committed to this view.

\section{Four Metatheorethical Positions}

I have argued that foreseeable noncompliance gives rise to three possible feasibility constraints on the concept of justice: the ability constraint, the motivational constraint and the institutional constraint. While the three constraints have so far been considered in isolation, it is now time to take a closer look at the relation between them. I will argue that the three constraints constitute a sequence in the sense that accepting the motivational constraint presupposes that we accept the ability constraint, and to accept the institutional constraint presupposes that we accept both previous constraints. If we add the possibility of rejecting the feasibility constraint on justice altogether, we get four metatheoretical positions that theorists could take vis-à-vis the feasibility constraint on justice. Depending on which position we adopt, we will be inclined to accept or reject proposed principles according to their demandingness. To illustrate this, the figure below borrows Estlund's terms 'impossible', 'hopeless' and 'hopeful' theory, which depict a falling scale of demandingness. (Estlund 2008, Chap. XIV) To these, I have added my own category 'enforceable' theory, signalling the moral significance of coercive institutions capable of assuring compliance with justice emphasized by the 
institutional constraint. Whether or not a certain constraint will actually produce the corresponding kind of theory is ultimately an empirical matter. To affirm one of the four metatheoretical positions should thus be understood as granting the acceptability of the corresponding kind of theory, rather than stating that principles of justice are or should be of the specified kind.

\begin{tabular}{llll}
\hline & Ability constraint & Motivational Constraint & Institutional constraint \\
\hline 1. Impossible theory & & & \\
2. Hopeless theory & $\mathrm{X}$ & & \\
3. Hopeful theory & $\mathrm{X}$ & $\mathrm{X}$ & \\
4. Enforceable theory & $\mathrm{X}$ & $\mathrm{X}$ & $\mathrm{X}$ \\
\hline
\end{tabular}

First, we could reject the feasibility constraint on justice altogether. In this case, we allow for impossible theory, that is, theory which promotes principles that we have no prospects of complying with. Of course, nothing says that rejecting the feasibility constraint will actually lead us to affirm this kind of theory. This depends on what the correct principles of justice, on the one hand, and the world, on the other, look like. All it says is that whether or not we are ever able to realize a proposed ideal or meet a proposed standard of justice is irrelevant for assessing the status of this ideal or standard.

Second, we could accept only the ability constraint on justice. To recapitulate, the ability constraint states that justice cannot demand that we perform acts which we could not perform, even if we were to try and not give up. This is the narrowest of the three interpretations of the feasibility constraint on justice. To accept the ability constraint but reject the two other constraints signals that we are prepared to accept hopeless theory, that is theory which falls short of demanding the impossible, but whose standards we still have good reason to believe that we will never meet (Estlund 2008, p. 264). Again, whether or not affirming the ability constraint will actually lead us to adopt this kind of standards is an empirical matter. But the mere fact that a proposed standard is hopeless will, on this account, not lead us to conclude that the principle behind it must be rejected.

Third, we could opt for the understanding of the feasibility constraint on justice that I have called the motivational constraint. This states that justice cannot demand that we perform acts which we, due to our human nature, cannot bring ourselves to perform. Now, if I am not able to do something, I will also not be able to bring myself to do it (at the very best, I could bring myself to try). To accept the motivational constraint, then, seems to presuppose that we also accept the ability constraint. To affirm these two constraints signals that we are not prepared to settle for anything less than hopeful theory, that is theory whose standards it is likely that we will be able to meet (Estlund 2008, p. 267). Still, whether or not this will actually result in a more concessive standard of justice than the previous constraints is ultimately an empirical question. At the end of the day, humans may turn out to be 
able to bring themselves to do all the things that they could do if they were to try and not give up. If so, the ability and motivational constraints will accept and reject exactly the same standards of justice, albeit for different reasons.

Last, we may affirm what I have called the institutional constraint on justice. If we do, we are concerned not only with the possibility and probability of meeting a certain standard of justice, but also with the standard's enforceability through the creation of coercive institutions. To affirm the institutional constraint seems to presuppose that we accept the ability and motivational constraints: our ability to make others do things seems to depend on them being able both to do and to bring themselves to do them. ${ }^{20}$ But, one may object, there may also be things that human beings can only do or bring themselves to do if incentivizing institutions are in place. Institutional arrangements may affect people's courage, creativity and endurance in ways that go beyond the individuals' control. Does not the fact that coercive institutions could enhance people's physical, mental or motivational capacities show that the institutional constraint may also produce a more demanding standard of justice than the ability and motivational constraints? No, it does not, at least not on the reading I propose here. On this reading, to reject the institutional constraint is not to say that justice must be achievable without coercive institutions (nobody, I think, would defend such a view), but only that justice must be achievable through the means provided by institutional arrangements or otherwise. What the institutional constraint adds is the assumption that the lack of coercive institutions that could ensure (a sufficient level of) compliance with a proposed principle is itself a reason to reject it as a principle of justice; hence enforceable theory. On this account, justice cannot demand of us to be as virtuous as we could (bring ourselves to) be, unless there are institutional arrangements that could render sufficiently sure that others will make a similar effort. If we can make people do all the things that they can do or will to do, the institutional constraint will produce the same standard of justice as the previous constraints. Yet, if there are things that we cannot make others do simply because they do not want to do them, the institutional constraint will produce a more concessive standard of justice than these.

\section{Conclusions}

I have argued that three different understandings of what 'ought implies can' means in political settings give rise to three possible feasibility constraints on the concept of justice: the ability constraint, the motivational constraint and the institutional constraint. Each of these places separate demands on proposed principles of justice. Affirming or rejecting the various constraints reveals our commitment to one out of four metatheoretical positions. Ranked according to demandingness (from highest to lowest), these allow for a conception of justice to promote impossible, hopeless, hopeful or only enforceable normative standards. Which constraints we affirm is

\footnotetext{
${ }^{20}$ For a divergent view, see Carens (1985), who argues that the status of a proposed principle depends on the theoretical possibility to institutionalize it, granted that all members of society are (at least initially, and to some extent) committed to, and hence motivated to comply with, the ideal.
} 
likely to depend on how 'practical' we hold the ideal of justice to be. If we think that justice must provide action-guiding recommendations for political agents in the real world, we tend to affirm more constraints than if we think that justice is an abstract philosophical ideal which may or may not have practical implications. Which, if any, of the constraints should we then affirm? This is a crucial question, and one that I have made no attempt to answer here. To do so would require an argument about the nature of normative concepts in general, and of justice in particular, problems too complex to be addressed within the scope of this paper. Still, I hope that the present discussion will facilitate future studies of this and related topics. My proposed distinction between the three feasibility constraints contributes to this purpose in at least three ways. First, it provides conceptual clarity and prevents misunderstandings. Second, it allows a shift in focus from the debate for or against the feasibility constraint on justice towards the pressing issue of what such a constraint would actually rule out. While the ability constraint only rules out principles that demand the strictly impossible, the motivational constraint also rules out demands which it is possible, yet highly improbable, that we fulfil. These two constraints invite us to think hard about the limits of human capacities; physical, mental and motivational. By contrast, the institutional constraint directs our thoughts towards the process of shaping and enforcing certain desired behaviours. As should be clear from the previous discussion, these matters are closely intertwined: which behaviours we could ensure through the creation of institutions depends on human capacities, and whether or not we will be able to fully exercise those capacities may depend on which institutional arrangements are available to us. Yet, once we see that the three constraints place different demands on principles of justice, we get a clearer picture of our reasons for rejecting a proposed principle on feasibility grounds. Third, the distinction may prove useful also in a broader context. Even if we reject all three feasibility constraints as constraints on the concept of justice, we may find them helpful for thinking about what justice may require at the level of (shorter- or longer-term) application. Though my concern here has been exclusively with constraints on first, or ideal, principles of justice, nothing prevents us from employing different constraints at different levels of analysis once we shift our focus from the ideal to the nonideal.

Acknowledgments Thanks to Ludvig Beckman, Michal Ben Noah, Eva Erman, David Estlund, Markus Furendal, Jonas Hultin Rosenberg, Robert Jubb, Aaron Maltais, Alexandra Segerberg and the participants of the Stockholm-Uppsala University workshop in political theory, December 2015, for reading and commenting on previous drafts of this paper. I also want to thank the anonymous reviewers for Res Publica for helpful comments and criticism.

Open Access This article is distributed under the terms of the Creative Commons Attribution 4.0 International License (http://creativecommons.org/licenses/by/4.0/), which permits unrestricted use, distribution, and reproduction in any medium, provided you give appropriate credit to the original author(s) and the source, provide a link to the Creative Commons license, and indicate if changes were made. 


\section{References}

Anderson, Elizabeth. 2010. The fundamental disagreement between luck egalitarians and relational egalitarians. Canadian Journal of Philosophy 40(sup 1): 1-23.

Barry, Christian, and Laura Valentini. 2009. Egalitarian challenges to global egalitarianism: A critique. Review of International Studies 35(3): 485-512.

Brennan, Geoffrey. 2013. Feasibility in optimizing ethics. Social Philosophy and Policy 30(1-2): 314-329.

Carens, Joseph H. 1985. Compensatory justice and social institutions. Economics and Philosophy 1(1): 39-67.

Carlson, Erik. 1999. The oughts and can of objective consequentialism. Utilitas 11(1): 91-96.

Chahboun, Naima. 2015. Nonideal theory and compliance-clarification. European Journal of Political Theory 14(2): 229-245.

Cohen, G.A. 1995. Self-ownership, freedom and equality. Studies in Marxism and social theory. Cambridge: Cambridge University Press.

Cohen, G.A. 1997. Where the action is: On the site of distributive justice. Philosophy \& Public Affairs 26(1): 3-30.

Cohen, G.A. 2008. Rescuing justice and equality. Cambridge, MA: Harvard University Press.

Estlund, David. 2008. Democratic authority: A philosophical framework. Princeton, NJ: Princeton University Press.

Estlund, David. 2011. Human Nature and the Limits (If Any) of Political Philosophy. Philosophy \& Public Affairs 38(3): 207-237.

Estlund, David. 2015. Reply to Wiens. European Journal of Political Theory, Epub ahead of print, August 30, 2015. doi:10.1177/1474885115602369.

Farrelly, Colin. 2007. Justice in ideal theory: A refutation. Political Studies 55(4): 844-864.

Galston, William A. 2010. Realism in political theory. European Journal of Political Theory 9(4): 385-411.

Geuss, Raymond. 2008. Philosophy and real politics. Princeton, NJ: Princeton University Press.

Gheaus, Anca. 2013. The feasibility constraint on the concept of justice. The Philosophical Quarterly 63(253): 445-464.

Gilabert, Pablo. 2009. The feasibility of basic socioeconomic rights: A conceptual exploration. The Philosophical Quarterly 59(237): 659-681.

Gilabert, Pablo. 2011. Feasibility and socialism. Journal of Political Philosophy 19(1): 52-63.

Gilabert, Pablo, and Holly Lawford-Smith. 2012. Political feasibility: A conceptual exploration. Political Studies 60(4): 809-825.

Hall, Edward. 2013. Political realism and fact-sensitivity. Res Publica 19(2): 173-181.

Horton, John. 2010. Realism, liberal moralism and a political theory of modus vivendi. European Journal of Political Theory 9(4): 431-448.

Howard-Snyder, Frances. 1997. The rejection of objective consequentialism. Utilitas 9(2): 241-248.

Jensen, Mark. 2009. The limits of practical possibility. The Journal of Political Philosophy 17(2): 168-184.

Jubb, Robert. 2009. Logical and epistemic foundationalism about grounding: The triviality of facts and principles. Res Publica 15(4): 337-353.

Jubb, Robert. 2012. Tragedies of non-ideal theory. European Journal of Political Theory 11(3): 229-246.

Jubb, Robert. 2015. Playing Kant at the court of King Arthur. Political Studies 63(4): 919-934.

Lawford-Smith, Holly. 2012. The feasibility of collectives' actions. Australasian Journal of Philosophy 9(3): 453-467.

Lawford-Smith, Holly. 2013a. Non-ideal accessibility. Ethical Theory and Moral Practice 16(3): 653-659.

Lawford-Smith, Holly. 2013b. Understanding political feasibility. The Journal of Political Philosophy 21(3): 243-259.

Mason, Andrew. 2004. Just constraints. British Journal of Political Science 34(1): 251-268.

Miller, David. 2013. Justice for earthlings: Essays in political philosophy. Cambridge: Cambridge University Press.

Nagel, Thomas. 1991. Equality and partiality. New York, NY: Oxford University Press.

Nagel, Thomas. 2005. The problem of global justice. Philosophy \& Public Affairs 33(2): 113-147.

Otsuka, Michael. 2008. Freedom of occupational choice. Ratio 21(4): 440-453. 
Philp, Marc. 2010. What is to be done? Political theory and political realism. European Journal of Political Theory 9(4): 466-484.

Philp, Marc. 2012. Realism without illusions. Political Theory 40(5): 629-649.

Räikkä, Juha. 1998. The feasibility condition in political theory. The Journal of Political Philosophy 6(1): 27-40.

Rawls, John. 1980. Kantian constructivism in moral theory. The Journal of Philosophy 77(9): 512-572.

Rawls, John. 1999. A theory of justice. Rev. edn. Cambridge, MA: The Belknap Press of Harvard University Press.

Rawls, John. 2001. Justice as fairness. A restatement. Cambridge, MA: The Belknap Press of Harvard University Press.

Rossi, Enzo. 2010. Reality and imagination in political theory and practice: On Raymond Geuss' realism. European Journal of Political Theory 9(4): 504-512.

Sangiovanni, Andrea. 2008. Justice and the priority of politics to morality. The Journal of Political Philosophy 16(2): 137-164.

Scheffler, Samuel. 1994. The rejection of consequentialism. Oxford: Clarendon.

Schmidtz, David. 2011. Nonideal theory: What it is and what it needs to be. Ethics 121(4): 772-796.

Sen, Amartya. 2006. What do we want from a theory of justice? Journal of Philosophy 103(5): 215-238.

Simmons, John A. 2010. Ideal and nonideal theory. Philosophy \& Public Affairs 38(1): 5-36.

Sleat, Matt. 2013. Liberal realism. A realist theory of liberal politics. Manchester and New York, NY: Manchester University Press.

Stemplowska, Zofia. 2008. What's ideal about ideal theory? Social Theory and Practice 34(3): 319-340.

Stemplowska, Zofia, and Adam Swift. 2012. Ideal and nonideal theory. In The Oxford handbook of political philosophy, ed. David Estlund, 373-390. Oxford: Oxford University Press.

Tan, Kok-Chor. 2004. Justice and personal pursuits. Journal of Philosophy 101(7): 331-362.

Valentini, Laura. 2012. Ideal vs. non-ideal theory: A conceptual map. Philosophy Compass 7(9): 654-664.

Wiens, David. 2014. 'Going evaluative' to save justice from feasibility: A pyrrhic victory. The Philosophical Quarterly 64(255): 301-307.

Wiens, David. 2015a. Against ideal guidance. The Journal of Politics 77(2): 433-446.

Wiens, David. 2015b. Motivational limitations on the demands on justice. European Journal of Political Theory, Epub ahead of print April 7, 2015. doi:10.1177/1474885115578446.

Wolff, Jonathan. 1998. Fairness, respect and the egalitarian ethos. Philosophy \& Public Affairs 27(2): 97-122. 